\title{
Serum calcium levels are not associated with coronary heart disease
}

This article was published in the following Dove Press journal:

Vascular Health and Risk Management

2 September 2013

Number of times this article has been viewed

\section{Yuelong Jin* \\ Lianping $\mathrm{He}^{*}$ \\ Quanhai Wang \\ Yan Chen \\ Xiaohua Ren \\ Hui Tang \\ Xiuli Song \\ Lingling Ding \\ Qin Qi \\ Zhiwei Huang \\ Jiegen Yu \\ Yingshui Yao}

Department of Preventive Medicine, Wannan Medical College, Wuhu,

People's Republic of China

*These authors contributed equally to this work
Correspondence: Yingshui Yao

Department of Preventive Medicine, Wannan Medical College,

22 Wenchangxi Road, Yijiang District,

Wuhu City, Anhui Province 241002,

People's Republic of China

Tel +86 I3053269969

Email yingshuiyao@163.com
Background: Numerous studies have reported that low calcium intake is related to a higher prevalence of cardiovascular disease. However, the relationship between serum calcium and coronary heart disease is unclear. The purpose of this study was to compare serum calcium levels in patients with coronary heart disease and those in healthy individuals.

Methods: This retrospective, case-control study conducted in the People's Republic of China comprised 380 cases and 379 controls. Serum calcium levels, blood lipids, and anthropometric measurements were measured in both groups. The Student's unpaired $t$-test or Chi-square test was used to compare differences between cases and controls. Pearson's partial correlation coefficient was used to determine the association between serum calcium, blood lipids, and blood pressure in both groups.

Results: Our results indicate that the average level of serum calcium in cases was higher than in controls. Serum calcium levels showed no correlation with any parameter except for triglycerides in either group.

Conclusion: Overall, these data suggest that serum calcium has no influence on coronary heart disease or triglyceride levels in the general population.

Keywords: serum calcium, hypertension, blood lipids

\section{Introduction}

Cardiovascular disease is the leading source of global disease burden. ${ }^{1-3}$ Numerous epidemiologic studies have reported that the prevalence of cardiovascular disease is high in the People's Republic of China. ${ }^{4,5}$ Also, a Markov computer simulation model showed that future risk of cardiovascular disease would increase by more than $50 \%$ between 2010 and 2030. ${ }^{6}$ A recent study demonstrated a weak causal relationship between the hardness of drinking water and mortality from cardiovascular disease in males. ${ }^{7}$ Another study documented that individuals who consume hard water rich in calcium and magnesium have a lower mortality rate from circulatory disease than those who consume soft water. However, some researchers have drawn the opposite conclusion, ie, that there is no association between changes in the hardness or calcium content of drinking water and cardiovascular mortality. ${ }^{8}$ Also, individual calcium intake was not unrelated to cardiovascular endpoints. ${ }^{9}$ One possible reason for this is that calcium ions cannot be completely absorbed after ingestion. More recent studies have shown that serum calcium may influence the level of high-density lipoprotein (HDL) cholesterol and decrease the level of low-density lipoprotein (LDL) cholesterol. ${ }^{10,11}$ Given that dyslipidemia is a major risk factor for coronary heart disease, the relationship between serum calcium levels and coronary heart disease should be investigated. Therefore, this 
study was carried out to evaluate the relationship between serum calcium levels in patients with coronary heart disease and healthy individuals and to investigate the correlation between serum calcium levels, blood lipid parameters, and blood pressure in both groups.

\section{Subjects and methods Participants}

Initially, routine health screening was performed in a total of 2,746 subjects who attended the Anhui Normal University in the east of the People's Republic of China from August 2006 to September 2006. All subjects were subjected to full history-taking and clinical examination. All those with the diagnosis of angina pectoris and whom the existence of coronary artery disease had been proved upon angiography, according to the diagnostic criteria of angina pectoris in coronary heart disease prepared by World Health Organization in 1979, 380 subjects met the above criteria of angina pectoris, and 379 healthy individuals matched with cases in age and sex were designated as the controls. All subjects agreed to provide their personal information, were informed regarding the purpose and procedures of our study, and gave their written informed consent. The study was approved by the ethics committee at Wannan Medical College.

\section{Blood pressure and anthropometric measurements}

Blood pressure was measured three times in the seated position using a mercury sphygmomanometer, and the three measurements were averaged for systolic and diastolic pressure. Height and weight were measured at least three times for each subject. Height was measured using a standard stadiometer following the study protocol, and weight in kilograms was measured on an electronic scale. Body mass index was calculated as weight $(\mathrm{kg}) /$ height $\left(\mathrm{m}^{2}\right)$.

\section{Collection of blood samples and analysis of biochemical indices}

During health screening, $10 \mathrm{~mL}$ of venous blood was collected into an evacuated blood collection tube. Serum was separated by centrifugation at $600 \mathrm{~g}$ for 10 minutes. Serum triglycerides and total cholesterol were measured using a commercial kit based on enzymatic principles, and the HDL cholesterol content was determined by the colorimetric method after separating LDL and very LDL using dextran sulfate- $\mathrm{Mg}^{2+}$ sedimentation. ${ }^{12}$ Serum LDL cholesterol was calculated by the Friedewald formula ${ }^{13}$ using triglycerides, total cholesterol, and HDL cholesterol values. The total serum calcium level was measured using the ADVIA 2400 (Siemens Healthcare Diagnostics, Malvern, PA, USA) with colorimetry.

\section{Statistical analysis}

Data analyses were performed using the $\mathrm{R}$ software programming language. ${ }^{14}$ The Student's unpaired $t$-test was used for comparison of quantitative data. The Chi-square test was used to compare the sex distribution between cases and controls. Pearson's partial correlation coefficient was used to investigate the relationship between serum calcium, blood lipids, and blood pressure after adjustment for age, sex, body mass index, height, and weight. All statistical tests were two-sided, and a value of $P<0.05$ was considered to be statistically significant.

\section{Results}

\section{General characteristics}

Among the total 759 subjects identified, 379 subjects served as controls and 380 subjects as cases with coronary heart disease. The baseline characteristics of the controls and cases are shown in Table 1 . The mean age of the controls and cases was $67.48 \pm 8.16$ years and $67.71 \pm 8.47$ years, respectively. No significant differences were found in age, height, sex distribution, diastolic blood pressure, blood lipid levels (total cholesterol, HDL cholesterol,

Table I General characteristics of controls and cases with coronary heart disease

\begin{tabular}{|c|c|c|c|c|c|}
\hline \multirow[t]{2}{*}{ Parameter } & \multicolumn{2}{|c|}{$\begin{array}{l}\text { Controls } \\
(n=379)\end{array}$} & \multicolumn{2}{|c|}{$\begin{array}{l}\text { Cases } \\
(n=380)\end{array}$} & \multirow[t]{2}{*}{$P$-value } \\
\hline & $\begin{array}{l}\text { Mean } \\
\text { or } \%\end{array}$ & SD & $\begin{array}{l}\text { Mean } \\
\text { or } \%\end{array}$ & SD & \\
\hline Age (years) & 67.48 & 8.16 & 67.71 & 8.47 & 0.697 \\
\hline \multicolumn{6}{|l|}{$\operatorname{Sex}(\%)$} \\
\hline Male & 63.1 & & 62.6 & & $0.604^{\mathrm{a}}$ \\
\hline Female & 36.9 & & 37.2 & & \\
\hline Height (m) & 1.63 & 0.08 & 1.63 & 0.08 & 0.630 \\
\hline Weight (kg) & 60.99 & 9.91 & 64.25 & 10.42 & 0.000 \\
\hline Body mass index $\left(\mathrm{kg} / \mathrm{m}^{2}\right)$ & 22.94 & 3.01 & 24.08 & 3.22 & 0.000 \\
\hline $\mathrm{SBP}(\mathrm{mmHg})$ & 130.26 & 18.81 & 134.88 & 18.88 & 0.002 \\
\hline $\mathrm{DBP}(\mathrm{mmHg})$ & 77.65 & 10.27 & 78.14 & 10.01 & 0.536 \\
\hline Serum calcium (mmol/L) & 2.54 & 0.15 & 2.57 & 0.14 & 0.038 \\
\hline Total cholesterol (mg/dL) & 5.56 & 0.89 & 5.47 & 0.90 & 0.12 \\
\hline HDL cholesterol (mg/dL) & 1.34 & 0.32 & 1.28 & 0.31 & 0.60 \\
\hline LDL cholesterol (mg/dL) & 3.46 & 0.79 & 3.39 & 0.82 & 0.249 \\
\hline Triglycerides (mg/dL) & 1.66 & 1.07 & 1.74 & 1.23 & 0.366 \\
\hline
\end{tabular}

Note: ${ }^{P}$-value show from Chi-square test comparing sex in the coronary heart disease group with controls.

Abbreviations: SBP, systolic blood pressure; DBP, diastolic blood pressure; $\mathrm{CHD}$, coronary heart disease; HDL, high-density lipoprotein; LDL, low-density lipoprotein; SD, standard deviation. 
LDL cholesterol, and triglycerides) between controls and cases. However, average weight, body mass index, systolic blood pressure, and serum calcium were higher in cases than in controls.

\section{Correlation between serum calcium levels, blood lipids, and blood pressure}

Table 2 shows the relationship between serum calcium, blood pressure, and blood lipids in both groups after adjustment for age, sex, body mass index, height, and weight. The results show that the serum calcium level was positively correlated with triglycerides in both groups $(P<0.05)$ but not with any other parameters $(P>0.05)$.

\section{Discussion}

The present study examined serum calcium levels, blood lipids, and blood pressure in subjects with and without coronary heart disease. Our results show that serum calcium was higher in cases than in controls. Sabanayagam and Shankar ${ }^{15}$ reported that higher serum calcium levels were positively correlated with hypertension in a representative sample of US adults, which is consistent with our findings. Further, Cook et al have shown that myeloperoxidase-mediated modulation of intracellular calcium ion levels may exacerbate endothelial dysfunction, a key early event in hypertension. ${ }^{16}$ A possible explanation is that higher serum calcium levels may influence the risk of coronary heart disease via blood pressure. However, a recent short-term study showed that supplementation with $2.25 \% \mathrm{CaCO}_{3}$ can reduce LDL cholesterol. ${ }^{17}$

In our study, the serum calcium level did not correlate with any parameter except for triglycerides in either group after adjusting for age, sex, body mass index, height, and weight. Other findings were that triglyceride levels had a significant positive correlation with serum calcium in the normotensive group and that LDL cholesterol had

Table 2 Correlation between serum calcium levels, blood lipids, and blood pressure

\begin{tabular}{|c|c|c|c|c|}
\hline \multirow[t]{2}{*}{ Parameter } & \multicolumn{2}{|c|}{$\begin{array}{l}\text { Control group } \\
(n=379)\end{array}$} & \multicolumn{2}{|c|}{$\begin{array}{l}\text { CHD group } \\
(n=380)\end{array}$} \\
\hline & $r$ & $P$-value & $r$ & P-value \\
\hline Total cholesterol & -0.033 & 0.583 & 0.028 & 0.0635 \\
\hline HDL cholesterol & -0.021 & 0.725 & -0.002 & 0.968 \\
\hline LDL cholesterol & -0.110 & 0.064 & -0.090 & 0.122 \\
\hline Triglycerides & 0.134 & 0.024 & 0.168 & 0.004 \\
\hline SBP & -0.027 & 0.649 & -0.028 & 0.625 \\
\hline DBP & -0.026 & 0.664 & -0.056 & 0.335 \\
\hline
\end{tabular}

Abbreviations: SBP, systolic blood pressure; DBP, diastolic blood pressure; CHD, coronary heart disease; HDL, high-density lipoprotein; LDL, low-density lipoprotein. a negative correlation with serum calcium in males but not in females. However, a positive relationship between serum calcium and LDL cholesterol has been observed in premenopausal women. ${ }^{18}$ The relationship between serum calcium and blood lipids may be influenced by sex and racial differences. Torres et $\mathrm{al}^{19}$ reported that a higher dietary calcium intake could be associated with less global adiposity. Other researchers have reached a conclusion similar to ours, ie, that calcium consumption is related to lipoprotein metabolism and affects the blood lipid profile. ${ }^{20,21}$ Calcium absorption according to age and physiologic status and the role of daily calcium intake in the prevalence of coronary heart and other cardiovascular disease should be further investigated.

Serum calcium may be involved in regulating blood pressure by controlling vascular smooth muscle cell contractility and thus modulating peripheral vascular resistance. ${ }^{21,22}$ In addition, extracellular ionized calcium inhibits renin secretion by interacting with the calciumsensing receptor. ${ }^{23,24}$ However, a study of two cohorts that included whites and blacks did not suggest that molecular variations in the calcium-sensing receptor influence either sodium balance or blood pressure. The mechanisms by which calcium lowers blood lipid levels need further research. This study has several limitations, in particular its small sample size. Moreover, it was based on data derived from routine health screening and lacks detailed information on relevant factors such as diet and lifestyle. In conclusion, serum calcium levels were higher in patients with coronary heart disease than in controls. These data suggest the serum calcium does not influence the risk of coronary heart disease.

\section{Acknowledgment}

This research was supported by the National Natural Science Foundation of China (81072367), the Anhui Provincial Natural Science Foundation (090413126 and 1308085MH135), and the Provincial Natural Science Research Project of Anhui Colleges (KJ2008A098) and Wannan Medical key scientific research projects Engagement Fund (WK2013Z01).

\section{Disclosure}

The authors report no conflicts of interest in this work.

\section{References}

1. Kettle SM, Roebothan BV, West R. Prevalence of specific cardiovascular disease risk factors in young Newfoundland and Labrador adults living in urban and rural communities. Can J Rural Med. 2005;10(2): 81-85. 
2. Margetts B, Armstrong B, Binns C, Masarei J, McCall M. Prevalence of some risk factors for cardiovascular disease in rural Western Australian children. Community Health Stud. 1983;7(3):256-265.

3. Voukiklaris GE, Kafatos A, Dontas AS. Changing prevalence of coronary heart disease risk factors and cardiovascular diseases in men of a rural area of Crete from 1960 to 1991. Angiology. 1996;47(1):43-49.

4. He L, Tang X, Song Y, et al. Prevalence of cardiovascular disease and risk factors in a rural district of Beijing, China: a population-based survey of 58,308 residents. BMC Public Health. 2012;12:34.

5. Lao XQ, Zhang YH, Wong MC, et al. The prevalence of metabolic syndrome and cardiovascular risk factors in adults in southern China. BMC Public Health. 2012;12:64.

6. Moran A, Gu D, Zhao D, et al. Future cardiovascular disease in China: Markov model and risk factor scenario projections from the coronary heart disease policy model - China. Circ Cardiovasc Qual Outcomes. 2010;3(3):243-252.

7. Schroeder HA. Relations between hardness of water and death rates from certain chronic and degenerative diseases in the United States. J Chronic Dis. 1960;12:586-591.

8. Lake IR, Swift L, Catling LA, Abubakar I, Sabel CE, Hunter PR. Effect of water hardness on cardiovascular mortality: an ecological time series approach. J Public Health (Oxf). 2010;32(4):479-487.

9. Morris RW, Walker M, Lennon LT, Shaper AG, Whincup PH. Hard drinking water does not protect against cardiovascular disease: new evidence from the British Regional Heart Study. Eur J Cardiovasc Prev Rehabil. 2008;15(2):185-189.

10. De Bacquer D, De Henauw S, De Backer G, Kornitzer M. Epidemiological evidence for an association between serum calcium and serum lipids. Atherosclerosis. 1994;108(2):193-200.

11. Reid IR, Mason B, Horne A, et al. Effects of calcium supplementation on serum lipid concentrations in normal older women: a randomized controlled trial. Am J Med. 2002;112(5):343-347.

12. Warnick GR, Benderson J, Albers JJ. Dextran sulfate-Mg2+ precipitation procedure for quantitation of high-density-lipoprotein cholesterol. Clin Chem. 1982;28(6):1379-1388.

13. van Klaveren RJ, Hoet PH, Pype JL, Demedts M, Nemery B. Increase in gamma-glutamyltransferase by glutathione depletion in rat type II pneumocytes. Free Radic Biol Med. 1997;22(3):525-534.
14. Johns KA. The programming environment for statistical tabulation. Int J Biomed Comput. 1986;19(3-4):161-173.

15. Sabanayagam C, Shankar A. Serum calcium levels and hypertension among US adults. J Clin Hypertens (Greenwich). 2011;13(10): 716-721.

16. Cook NL, Viola HM, Sharov VS, Hool LC, Schoneich C, Davies MJ. Myeloperoxidase-derived oxidants inhibit sarco/endoplasmic reticulum $\mathrm{Ca} 2+-A T P a s e$ activity and perturb Ca2+ homeostasis in human coronary artery endothelial cells. Free Radic Biol Med. 2012;52(5):951-961.

17. Shahkhalili Y, Murset C, Meirim I, et al. Calcium supplementation of chocolate: effect on cocoa butter digestibility and blood lipids in humans. Am J Clin Nutr. 2001;73(2): 246-252.

18. Farhangi MA, Ostadrahimi A, Mahboob S. Serum calcium, magnesium, phosphorous and lipid profile in healthy Iranian premenopausal women. Biochem Med (Zagreb). 2011;21(3):312-320.

19. Torres MR, Ferreira Tda S, Carvalho DC, Sanjuliani AF. Dietary calcium intake and its relationship with adiposity and metabolic profile in hypertensive patients. Nutrition. 2011;27(6):666-671.

20. Vaskonen T, Mervaala E, Sumuvuori V, Seppanen-Laakso T, Karppanen H. Effects of calcium and plant sterols on serum lipids in obese Zucker rats on a low-fat diet. Br J Nutr. 2002;87(3): 239-245.

21. Zemel MB. Regulation of adiposity and obesity risk by dietary calcium: mechanisms and implications. J Am Coll Nutr. 2002;21(2): 146S-151S

22. Zemel MB. Nutritional and endocrine modulation of intracellular calcium: implications in obesity, insulin resistance and hypertension. Mol Cell Biochem. 1998;188(1-2):129-136.

23. Resnick LM, Laragh JH, Sealey JE, Alderman MH. Divalent cations in essential hypertension. Relations between serum ionized calcium, magnesium, and plasma renin activity. $N$ Engl J Med. 1983;309(15): 888-891.

24. Maillard MP, Tedjani A, Perregaux C, Burnier M. Calcium-sensing receptors modulate renin release in vivo and in vitro in the rat. J Hypertens. 2009;27(10):1980-1987.
Vascular Health and Risk Management

\section{Publish your work in this journal}

Vascular Health and Risk Management is an international, peerreviewed journal of therapeutics and risk management, focusing on concise rapid reporting of clinical studies on the processes involved in the maintenance of vascular health; the monitoring, prevention and treatment of vascular disease and its sequelae; and the involvement of

\section{Dovepress}

metabolic disorders, particularly diabetes. This journal is indexed on PubMed Central and MedLine. The manuscript management system is completely online and includes a very quick and fair peer-review system, which is all easy to use. Visit http://www.dovepress.com/ testimonials.php to read real quotes from published authors. 